\title{
Analisis Faktor Risiko Glomerulonefritis Akut Pasca Streptokokus pada Anak Di RSUP Prof. Dr. R. D. Kandou Manado
}

\author{
${ }^{1}$ Pirania Ch. Tatipang \\ ${ }^{2}$ Adrian Umboh \\ ${ }^{2}$ Praevilia M. Salendu
}

\author{
${ }^{1}$ Program Studi Pendidikan Dokter Fakultas Kedokteran Universitas Sam Ratulangi Manado \\ ${ }^{2}$ Bagian Ilmu Kesehatan Anak Fakultas Kedokteran Universitas Sam Ratulangi Manado \\ Email: tatipangchristy@gmailcom
}

\begin{abstract}
Acute post-streptococcal glomerulonephritis (APSGN) is a part of acute nephritic syndrome characterized by gross hematuria, edema, hypertension, and renal insufficiency. This APSGN is common in children, caused by infection of Streptococcus $\beta$-hemoliticus group A nephritogenic strain, and $97 \%$ of cases were in developing countries including Indonesia. This study was aimed to obtain the risk factors of APSGN and their association with APSGN. This was a retrospective descriptive study with a cross sectional design. Samples were medical record data of Prof. Dr. R. D. Kandou Hospital Manado during the period of January 2013-October 2017. There were 67 samples in this study consisted of 48 (71.6\%) cases of APSGN and 19 (25.3\%) cases without APSGN. The bivariate analysis found five variables related to APSGN incidence, as followed: male gender $(P=0.005)$, age $\geq 5$ years $(P=0.000)$, low socioeconomic status $(P=0.000)$, good nutrition $(P=0.000)$, and rainy season $(P=0.005)$. Parents' education was not related to APSGN incidence. Conclusion: The risk factors of APSGN in children were male gender, age $\geq 5$ years, low socioeconomic status, good nutritional status, and rainy season.
\end{abstract}

Keywords: APSGN, risk factors, children

\begin{abstract}
Abstrak: Glomerulonefritis akut pasca streptokokus (GNAPS) adalah bagian dari sindrom nefrotik akut (SNA) yang ditandai dengan gross hematuria, edema, hipertensi, dan insufisiensi ginjal. Gangguan ini sering terjadi pada anak-anak, disebabkan oleh infeksi kuman Streptococcus $\beta$-hemolyticus group A strain nephritogenic, dan $97 \%$ kasus terjadi di negara berkembang termasuk Indonesia. Penelitian ini bertujuan untuk mengetahui faktor risiko GNAPS dan hubungan faktor risiko tersebut dengan kejadin GNAPS. Jenis peneltiian ialah deskriptif retrospektif dengan desain potong lintang. Pengambilan sampel menggunakan data rekam medik RSUP Prof. R. D. Kandou Manado periode Januari 2013-Oktober 2017. Terdapat 67 sampel terdiri dari 48 (71,6\%) kasus GNAPS dan $19(25,3 \%)$ kasus yang tidak mengalami GNAPS. Berdasarkan analisis bivariat di temukan 5 varibel yang berhubungan dengan kejadian GNAPS yaitu jenis kelamin laki-laki $P=0,005)$, usia $\geq 5$ tahun $(P=0,000)$, status sosial ekonomi rendah $(P=0,000)$, gizi baik $(P=0,000)$, dan musim hujan $(P=0,005)$. Faktor risiko yang tidak berhubungan dengan kejadian GNAPS ialah pendidikan orang tua $(P=0,20)$. Simpulan: Faktor risiko GNAPS pada anak ialah jenis kelamin laki-laki, usia $\geq 5$ tahun, status sosial ekonomi rendah, status gizi, dan musim hujan.
\end{abstract}

Kata Kunci: GNAPS, faktor risiko, anak

Glomerulonefritis akut pasca streptokokus (GNAPS) adalah bagian dari acute nephritic syndrome yang ditandai dengan gross hematuria, edema, hipertensi dan insufisiensi ginjal. GNAPS sering terjadi pada anak-anak, di sebabkan oleh infeksi 
kuman Streptokokus $\beta$-hemoliticus grup A
strain nephritogenic.

Glomerulonefritis akut pasca streptokokus sering terjadi pada anak usia 5-12 tahun, jarang pada anak di bawah 3 tahun. Penyebabnya karena pada usia 5-12 tahun merupakan usia sekolah, di mana mudah terpapar dengan agen infeksi. ${ }^{2,3}$ Sekitar 97\% kasus GNAPS terjadi di negara berkembang dan berkurang di negara industri atau negara maju. ${ }^{1}$ Terbukti, selama 2-3 dekade terakhir, kejadian GNAPS telah menurun di Amerika Serikat dan juga di negara lain, seperti Jepang, Eropa Tengah, Inggris Raya dan korea selatan. ${ }^{2,3}$ Hal ini berkaitan dengan kondisi higiene yang baik, lingkungan yang sehat, serta penggunaan antibiotik. ${ }^{1,2}$ WHO memperkirakan kasus GNAPS terjadi kirakira 472000 kasus setiap tahunnya secara global dengan 5000 kematian setiap tahunnya. Kira-kira 404000 kasus di laporakan terjadi pada anak-anak dan 456 terjadi pada negara berkembang. ${ }^{4}$

Umumnya GNAPS terjadi pada daerah beriklim tropis dan biasanya berdampak pada anak-anak dengan tingkat ekonomi yang rendah. Penyakit ini biasanya terjadi secara sporadik tetapi peningkatan insidensi kasus terjadi secara epidemik pada tempat dengan komunitas yang memiliki populasi tempat tinggal di lingkungan yang padat penduduk, higiene kurang baik, kondisi dengan insidens malnutrisi yang tinggi. Indonesia merupakan negara beriklim tropis. Sebanyak $68,9 \%$ penderita GNAPS berasal dari keluarga dengan sosial ekonomi yang rendah dan $82 \%$ pada keluarga berpendidikan rendah. ${ }^{4,5}$

Selain faktor kuman Streptokokus $\beta$ hemoliticus grup A strain nephritogenic, terjadinya GNAPS dipengaruhi juga oleh beberapa faktor pejamu seperti usia, jenis kelamin, keadaan sosial ekonomi,genetik, status gizi. dan musim. Musim juga merupakan faktor yang dapat memengaruhi kejadian GNAPS sebab infeksi tenggorokan lebih sering terjadi pada musim dingin, awal musim semi, dan musim hujan sedangkan piodermia lebih sering terjadi pada akhir musim panas dan musim gugur. ${ }^{6}$
Pasien yang berjenis kelamin laki-laki memiliki perbandingan yang lebih tinggi di bandingkan perempuan. ${ }^{7}$ Hal ini mungkin disebabkan karena anak laki-laki lebih sering berada di luar rumah sehingga rentan terpapar dengan kuman penyebab infeksi. ${ }^{8}$

\section{METODE PENELITIAN}

Jenis penelitian ini ialah analitik deskriptif restrospektif dengan desain potong lintang menggunakan datar rekam medik pasien anak yang mengalami sindrom nefritik akut (SNA) yang didiagnosis dengan GNAPS dan yang tidak pada periode Januari 2013-Oktober 2017.

Cara pengambilan sampel menggunakan teknik purposive sampling.

\section{HASIL PENELITIAN}

Total pasien yang dirawat di ruang rawat inap bagian anak RSUP Prof. R. D. Kandou Manado yaitu sebanyak 69 pasien SNA dan yang mememenuhi kriteria inklusi sebanyak 67 orang terdiri dari 48 orang pasien yang positif GNAPS dan 19 orang pasien yang negatif GNAPS.

Pada penelitian ini pasien anak dengan GNAPS berjumah 48 orang, terdiri dari laki-laki 30 orang $(62,5 \%)$ dan perempuan 18 orang $(37,5 \%)$. Pasien anak yang tidak didiagnosis dengan GNAPS berjumlah 19 orang, terdiri dari laki-laki 15 orang $(78,9 \%)$ dan perempuan 4 orang $(21,1 \%)$. Berdasarkan data ini jenis kelamin baik yang menderita GNAPS dan yang tidak, yang paling banyak menderita GNAPS ialah laki-laki sejumlah 30 orang $(62,5 \%)$ dan yang tidak 15 orang $(78,9 \%)$. Hasil uji statistik mendapatkan nilai $X^{2}=7,896, \mathrm{df}=1$, $P=0,005 \quad(P<0,05)$. Hasil ini menyatakan terdapat hubungan bermakna antara jenis kelamin dan GNAPS (Tabel 1).

Dari 48 pasien yang positif GNAPS di dapatkan yang berusia $<5$ tahun sejumlah 5 orang $(10,4 \%)$ dan yang berusia $\geq 5$ tahun ialah 43 orang $(89,6 \%)$. Pasien yang tidak didiagnosis GNAPS sebanyak 19 orang anak, yang berusia $<5$ tahun $1(5,3 \%)$ orang dan yang $\geq 5$ tahun ialah 18 orang $(94,7 \%)$. Berdasarkan data ini anak yang paling banyak mengalami GNAPS dan yang tidak 
mengalami GNAPS ialah berusia $\geq 5$ tahun yang berjumlah 43 orang $(89,6 \%)$, dan 18 orang $(94,7 \%)$. Berdasarkan uji statistik diperoleh nilai $\mathrm{X}^{2}=45,149 \mathrm{df}=1, P=0,000$ $(P<0,05)$. Hasil ini menyatakan terdapat hubungan bermakna antara usia dan kejadian GNAPS (Tabel 2).

Dari keseluruhan jumlah pasien, orang tua pasien dengan GNAPS yang tidak tamat SMA (pendidikan rendah) berjumlah 16 orang $(33,3 \%)$ dan yang tamat SMA (pendidikan tinggi) berjumlah 32 orang $(66,7 \%)$. Pasien yang tidak didiagnosis GNAPS memiliki orang tua yang berpendidikan rendah 6 orang $(31,6 \%)$ dan pendidikan tinggi 14 orang $(68,4 \%)$. Dari keseluruhan data orang tua pasien yang didiagnosis dengan GNAPS dan yang tidak, yang paling banyak berpendidikan tinggi yaitu sejumlah 32 orang $(66,7 \%)$ dan 13 orang $(68,4 \%)$. Berdasarkan uji statistk $\mathrm{X}^{2}=5,388 ; \mathrm{df}=1 ; \quad P=0,200 ;$ menunjukkan tidak terdapat hubungan bermakna antara pendidikan orang tua dan GNAPS (Tabel 3).

Jumlah pasien yang didiagnosis GNAPS yang berstatus sosial ekonomi kelas atas ialah 6 orang (12,5\%), kelas menengah 6 orang $(12,5 \%)$ dan kelas bawah 36 orang $(75 \%)$. Pasien yang tidak didiagnosis dengan GNAPS yang memiliki soseial ekonomi kelas atas 4 orang $(21,1 \%)$, kelas menengah 1 orang $(5,3 \%)$ dan kelas bawah 14 orang $(73,3 \%)$. Berdasarkan distribusi status sosial ekonomi, yang paling banyak pasien GNAPS berstatus sosial ekonomi kelas bawah 36 orang $(75 \%)$. Demikin juga pasien yang tidak didiagnosis dengan GNAPS lebih banyak berstatsus sosial kelas bawah yaitu 14 orang $(73,3 \%)$. Berdasarkan uji statistik ini nilai $\quad X^{2}=51,612 ; \quad \mathrm{df}=2 ; \quad P=0,000$ menyatakan terdapat hubungan bermakna antara status sosial ekonomi dan GNAPS (Tabel 4).

Jumlah pasien yang didiagnosis dengan GNAPS yang memiliki gizi buruk ialah 2 orang $(4,2 \%)$, status gizi kurang 6 orang $(12,5 \%)$, status gizi baik 36 orang $(75 \%)$, status gizi lebih 2 orang $(4,2 \%)$, obesitas 2 orang (4,2\%). Yang tidak didiagnosis dengan GNAPS bejumlah 19 orang yang memiliki gizi buruk $0(0,00 \%)$, gizi kurang 3 orang $(15,8 \%)$, Gizi baik 14 orang $(73,7 \%)$, gizi lebih 1 orang $(5,3 \%)$ serta obesitas 1 orang $(5,3 \%)$. Berdasarkan distribusi paling banyak pasien yang di diagnosis dengan GNAPS sama dengan yang tidak GNAPS, memiliki status gizi baik, yaitu berjumlah 35 orang $(72,9 \%)$, dan 17 orang $(73,9 \%)$. Berdasarkan uji statistik $\quad X^{2}=127,254 ; \quad \mathrm{df}=4 ; \quad P=0,000$, terdapat hubungan bermakna antara status gizi dan GNAPS (Tabel 5).

Jumlah pasien yang di diagnosis dengan GNAPS yang memiliki gizi buruk ialah 2 orang $(4,2 \%)$, status gizi kurang 6 orang (12,5\%), status gizi baik 36 orang (75\%), status gizi lebih 2 orang (4.2\%), obesitas 2 orang $(4,2 \%)$. Yang tidak didiagnosis dengan GNAPS bejumlah 19 orang yang memiliki gizi buruk $0(0,00 \%)$, gizi kurang 3 orang $(15,8 \%)$, gizi baik 14 orang $(73,7 \%)$, gizi lebih 1 orang $(5,3 \%)$ serta obesitas 1 orang $(5,3 \%)$. Berdasarkan distribusi paling banyak pasien yang di diagnosis dengan GNAPS sama dengan yang tidak GNAPS, memiliki status gizi baik, yaitu berjumlah 35 orang $(72,9 \%)$, dan 17 orang $(73,9 \%)$. Berdasarkan uji statistk $\mathrm{X}^{2}=7,896 ; \mathrm{df}=1 ; P=0,005$, terdapat hubungan bermakna antara status gizi dan GNAPS (Tabel 6)..

Tabel 1. Distribusi berdasarkan jenis kelamin dan hasil uji statistik

\begin{tabular}{cccc}
\hline Jenia kelamin & Tidak GNAPS & GNAPS & \\
\hline Laki-laki & $15(78,9 \%)$ & $30(62,5 \%)$ & $45(67,2 \%)$ \\
Perempuan & $4(21,1 \%)$ & $18(37,5 \%)$ & $22(32,8 \%)$ \\
Total & $19(100 \%)$ & $48(100 \%)$ & $67(100 \%)$ \\
& Chi-Square $\mathrm{X}^{2}=7,896 \mathrm{df}=1 \mathrm{p}=0,005$ & \\
\hline
\end{tabular}


Tabel 2. Distribusi berdasarkan usia dan hasil uji statistik

\begin{tabular}{cccc}
\hline Usia (Tahun) & Tidak GNAPS & GNAPS & Total \\
\hline$<5$ & $1(5,3 \%)$ & $5(10,4 \%)$ & $7(9.9 \%)$ \\
$\geq 5$ & $18(94,7 . \%)$ & $43(89,6 \%)$ & $64(90,1 \%)$ \\
Total & $19(100 \%)$ & $48(100 \%)$ & $67(100,0 \%)$ \\
& $\mathrm{X}^{2}=45.149 \mathrm{df}=1 \mathrm{p}=0.000$ & \\
\hline
\end{tabular}

Tabel 3. Distribusi pendidikan orang tua dan hasil uji statistik

\begin{tabular}{cccc}
\hline $\begin{array}{c}\text { Pendidikan } \\
\text { orang tua }\end{array}$ & Tidak GNAPS & GNAPS & Total \\
\hline Rendah & $6(31,6 \%)$ & $16(33,3 \%)$ & $25(35,2 \%)$ \\
Tinggi & $13(68,4 \%)$ & $32(66,70 \%)$ & $46(64,80 \%)$ \\
Total & $19(100 \%)$ & $48(100 \%)$ & $67(100 \%)$ \\
& $\mathrm{X}^{2}=5.388 \mathrm{df}=1 \mathrm{p}=0.200$ & \\
\hline
\end{tabular}

Tabel 4. Distribusi status sosial ekonomi dan hasil uji statistik

\begin{tabular}{cccc}
\hline $\begin{array}{c}\text { Status } \\
\text { sosial ekonomi }\end{array}$ & $\begin{array}{c}\text { Tidak } \\
\text { GNAPS }\end{array}$ & GNAPS & Total \\
\hline Kelas atas & $4(21,1 \%)$ & $6(12,50 \%)$ & $10(14,1 \%)$ \\
Kelas menengah & $1(5,3 \%)$ & $6(12,50 \%)$ & $7(9,90 \%)$ \\
Kelas bawah & $14(73,7 \%)$ & $36(75 \%)$ & $54(76,1 \%)$ \\
Total & $23(100 \%)$ & $48(100 \%)$ & $67(100 \%)$ \\
& $\mathrm{X}^{2}=51.612 \mathrm{df}=2 \mathrm{p}=0.000$ & \\
\hline
\end{tabular}

Tabel 5. Distribusi status gizi dan hasil uji statistik

\begin{tabular}{cccc}
\hline Status Gizi & Tidak GNAPS & GNAPS & Total \\
\hline Gizi buruk & $0(0,00 \%)$ & $2(4,2 \%)$ & $2(2,80 \%)$ \\
Gizi kurang & $3(15,8 \%)$ & $6(12,5 \%)$ & $11(15,50 \%)$ \\
Gizi baik & $14(73,7 \%)$ & $36(75 \%)$ & $52(73,20 \%)$ \\
Gizi lebih & $1(5,3 \%)$ & $2(4,2 \%)$ & $3(4,20 \%)$ \\
Obesitas & $1(5,3 \%)$ & $2(4,2 \%)$ & $3(4.20 \%)$ \\
Total & $19(100 \%)$ & $48(100 \%)$ & $67(100 \%)$ \\
& $\mathrm{X}^{2}=127.254 \mathrm{df}=4 \mathrm{p}=0.000$ & \\
\hline
\end{tabular}

Tabel 6. Distribusi berdasarkan musim dan hasil uji statistik

\begin{tabular}{cccc}
\hline Musim & Tidak GNAPS & GNAPS & Total \\
\hline Hujan & $11(57,9 \%)$ & $34(70,8 \%$ & $48(67,60 \%)$ \\
Panas & $8(42,1 \%)$ & $14(29,2 \%)$ & $19(32,40 \%)$ \\
Total & $19(100 \%)$ & $48(100 \%)$ & $62(100 \%)$ \\
& $\mathrm{X}^{2}=7.896 \mathrm{df}=1 \mathrm{p}=0.005$ & \\
\hline
\end{tabular}

\section{BAHASAN}

Dalam penelitan ini di temukan pasien GNAPS paling banyak tejadi pada anak laki-laki. Keadaan ini menunjukkan bahwa jenis kelamin laki-laki memilki risiko lebih tinggi terkena GNAPS. Hal ini dibuktikan dengan uji statistik bivariat menggunakan uji chi-square. Jenis kelamin $(P=0,005)$ 
memiliki hubungan bermakna dengan terjadinya GNAPS. Penelitian ini didukung oleh penelitian oleh Idhate et al. ${ }^{9}$ yang mendapatkan pasien laki-laki lebih banyak dibandingkan perempuan. Penelitian multisenter di 11 rumah sakit pendidikan di Indonesia pada tahun 2005 juga menunjukkan hal yang sama. ${ }^{10}$ Penelitian oleh Agung $\mathrm{R}$ et al. ${ }^{7}$ juga menunjukkan pasien GNAPS lebih banyak pada anak laki-laki di bandingkan perempuan. Menurut Lufyan ${ }^{8}$ umumnya anak laki-laki lebih aktif dibandingkan anak perempuan sehingga lebih besar kemungkinan untuk terpapar dengan lingkungan dan terinfeksi kuman. Belum terdapat penelitian yang pasti mengenai hal ini, tetapi kebanyakan pasien GNAPS berjenis kelamin laki-laki.

Kelompok usia yang paling sering terpapar dengan kuman penyebab GNAPS berada pada usia sekolah yaitu 5-12 tahun dan jarang pada usia di bawah 3 tahun. Hal ini karena pada usia sekolah anak sudah mulai sering berada di luar rumah dan lebih aktif sehingga mudah terpapar dengan kuman penyebab GNAPS. ${ }^{1}$ Data pada penelitian ini menunjukan hal yang sama dari 48 orang pasien angka kejadian terting-gi terjadi pada usia $\geq 5$ tahun yaitu 6-9 tahun 25 orang dan 10-13 tahun 15 orang. Berdasarkan uji statistik didapatkan hubungan bermakna antara usia dan kejadian GNAPS pada anak. Hasil ini didukung oleh penelitian Suhardi et al..$^{5}$ yang menunjukkan anak berusia di atas 5 tahun memiliki risiko yang lebih tinggi terkena GNAPS. Sama halnya dengan penelitian Lufyan et al. ${ }^{8}$ yang melaporkan bahwa kelompok usia yang paling banyak menderita GNAPS ialah di atas 5 tahun yaitu 5-9 tahun. Menurut Shah et al. ${ }^{11}$ di katakan kelompok usia yang paling banyak menderita GNAPS ialah lebih dari 5 tahun yaitu berada pada kelompok usia sekolah yaitu 5-15 tahun.

Keadaan sosial ekonomi turut memengaruhi terjadinya GNAPS. Kliegman RM et $a l^{1}$ 97\% pasien GNAPS tinggal di negara berkembang dan memiliki status sosial ekonomi rendah. Indonesia merupakan negara berkembang yang masih memiliki banyak penduduk miskin yang berstatus ekonomi rendah. Status sosial ekonomi turut menunjang gaya hidup, serta prilaku yang sadar akan kesehatan. Pada Tabel 6 dari 48 orang pasien GNAPS sebagian besar memiliki status sosial rendah (kelas bawah) 36 orang dibanding pasien dengan status ekonomi kelas menengah 6 orang dan kelas atas 6 orang. Data tersebut menunjukkan pasien yang memiliki status sosial rendah (kelas bawah) memiliki faktor risiko yang lebih tinggi untuk menderita GNAPS. Hal ini didukung oleh ditemukannya hubungan bermakna antara status sosial ekonomi rendah dengan terjadinya GNAPS pada pasien. Selaras dengan penelitian yang telah dilakukan Suhardi et al. ${ }^{5}$ dikatakan bahwa status ekonomi rendah memengaruhi kejadian GNAPS.

Pengetahuan akan kesehatan pada anak ditunjang dengan tingkat pendidikan orang tua. Tabel 3 menunjukkan lebih banyak orang tua pasien GNAPS yang tamat Sekolah Menengah Atas (pendidikan tinggi) yaitu 32 orang dibanding yang tidak tamat SMA (pendidikan rendah) yaitu berjumlah 16 orang. Data tersebut menunjukkan orang tua pasien yang didiagnosis GNAPS dan yang tidak lebih banyak yang berpendidikan tinggi (tamat SMA). Hasil uji analisis membuktikan bahwa pendidikan orang tua tidak memilki hubungan bermakna dengan kejadian GNAPS. Sejalan dengan penelitian yang di lakukan oleh Suhardi et al. ${ }^{5}$ didapatkan hasil orang tua pasien yang menderita GNAPS umumnya berpendidikan rendah. Menurut Blum ${ }^{12}$ faktor-faktor yang memengaruhi kesehatan ialah faktor keturunan, lingkungan, pelayanan kesehatan, dan perilaku. Tidak adanya hubungan antara pendidikan orang tua dan kejadian GNAPS berkaitan dengan keterbatasan pada penelitian ini yaitu hanya menggunakan data pada rekam medik sehingga faktor-faktor lain yang mungkin berhubungan dengan kesehatan pada anak seperti yang dikemukakan oleh Blum ${ }^{12}$ tidak dapat diidentifikasi oleh penulis.

Musim merupakan salah satu faktor pendukung terjadinya GNAPS. ${ }^{1}$ Indonesia merupakan negara beriklim tropis yang 
hanya memilki 2 musim yaitu musim hujan dan musim panas. Terjadinya GNAPS didahului dengan infeksi saluran pernapasan atas (ISPA) 1-2 minggu dan infeksi kulit (pioderma) 3-6 minggu. ISPA umunya terjadi pada musim hujan sedangkan pioderma pada musim panas. ${ }^{13}$ Penentuan musim di indonesia berbeda setiap daerah. Umumnya menurut Badan Meteorologi Klimatologi dan Geofisika (BMKG) Indonesia, musim hujan terjadi pada bulan Oktober-Maret, sedangkan musim panas pada bulan April-September. ${ }^{14}$ Pada penelitian ini ditemukan pasien yang dirawat di bangsal rawat inap bagian anak RSUP Prof. R. D. Kandou Manado berdasarkan pada waktu masuk rumah sakit, yang positif GNAPS kebanyakan berada saat musim hujan 33 orang $(68,8 \%)$ dibandingkan musim panas hanya 15 orang $(31,3 \%)$. Hasil uji statistik mendapatkan adanya hubungan bermakna antara musim dan kejadian GNAPS. Sejalan dengan peneltian Suhardi et al. ${ }^{5}$ yang menyatakan musim memiliki hubungan dengan kejadian GNAPS yang dibuktikan dengan data dan uji statistik yang telah dilakukan.

Glomerulonefritis akut pasca streptokokus merupakan penyakit yang dimediasi oleh sistem imun, sehingga status gizi turut memengaruhi terjadinya GNAPS pada anak. Smith et al. ${ }^{15}$ menyebutkan malnutrisi atau gizi buruk merupakan salah satu faktor risiko GNAPS. Hasil yang berbeda didapatkan pada penelitian ini, dari 48 pasien yang didiagnosis dengan GNAPS hanya $2(4,2 \%)$ orang yang memiliki gizi buruk sedangkan selebihnya didominasi oleh 6 orang gizi kurang (12,5\%), 35 orang gizi baik (72,9\%), 2 orang gizi lebih $(4,2 \%)$ dan 3 orang dengan obesitas $(6,3 \%)$. Hal ini menunjukkan bahwa tidak hanya anak yang memiliki gizi buruk (malnutrisi) yang dapat mengalami GNAPS tetapi anak yang memilki gizi baik juga berpeluang untuk mengalami GNAPS. Hal ini dibuktikan berdasarkan uji statistik yang menunjukkan hubungan bermakna antara status gizi dengan terjadinya GNAPS. Penelitian ini selaras dengan yang dilaporkan oleh Suhardi et al. ${ }^{5}$ bahwa terdapat hubungan antara status gizi dan kejadian GNAPS. Prevalensi status gizi anak di Sulawesi Utara menurut RISKESDAS tahun 2013 ditemukan gizi buruk sebanyak $3,7 \%$, gizi kurang $12,8 \%$, gizi baik $79 \%$, dan gizi lebih $4,5 \%{ }^{16}$ Pasien GNAPS yang ditemukan pada penelitian ini lebih banyak memiliki gizi baik berkaitan dengan hasil dari RISKESDAS yang ditemukan prevalensi status gizi anak di Sulawesi Utara didominasi oleh anak yang berstatus gizi baik.

\section{SIMPULAN}

Dari hasil penelitian dapat disimpulkan bahwa jenis kelamin laki-laki, usia $\geq 5$ tahun, status sosial ekonomi rendah (kelas bawah), musim hujan, serta status gizi merupakan faktor risiko dari glomerulonefritis akut pasca streptokokus (GNAPS), sedangkan pendidikan orang tua (pendidikan tinggi) bukan merupakan faktor risiko dari GNAPS.

\section{SARAN}

Disarankan untuk memberikan edukasi mengenai glomerulonefritis akut pasca streptokokus (GNAPS) beserta faktor risiko kepada para orang tua untuk mengurangi kejadian GNAPS.

\section{DAFTAR PUSTAKA}

1. Kliegman RM. Glomerulonephritis associated with infection. In: Pan CG, Avner ED, editors. Nelson Text Book Pediatrics (12th ed). Canada: Elsevier, 2016; p. 3612.

2. Bhimma R. Acute post streptococcal glomerulonephritis. 2016 Nov 2 [cited 2017 Sep 2]. Available from: http:// www.emedicine.medscape.com/article/ 980685/overview

3. Woo KS, Mi HS, Sook YY, Woo RJ, Soon SJ, Yil LK. Changes in acute poststreptococcal glomerulonephritis an observation study at a single Korean Hospital over two decades. Chil Kidney Dis. 2015;19:113-4.

4. Kher KK. Acute glomerular disease in children. The Open Urology \& Nephrology Journal. 2015;45;264-9.

5. Suhardi, Albar H, Rauf S, Daud D. The 
identification of acute post streptococcus glomerulonephritis risk factors in children. Int J Sci Res. 2015;4:71-7.

6. Pardede SO. Struktur Sel streptokokus dan patogenesis glomerulonefritis akut pasca streptokokus. Sari Perdiatri. 2009;11:56-62.

7. Hidayani AR, Umboh A, Gunawan S. Profil glomerulonefritis akut pasca streptokokus pada anak yang dirawat di Bagian Ilmu Kesehatan Anak RSUP Prof. Dr. R. D. Kandou Manado. eCl. 2016;4:2-3.

8. Lufyan R, Suarta IK, Nilawati $P$. Karakteristik glomerulonefritis akut pasca streptokokus pada anak di RSUP Sanglah Denpasar tahun 2012-2015. Medicina. 2017;45;124.

9. Idhate T, Zaki SA, Shanbag P. Cardiac status in children with acute post glomerulonephritis. Saudi J Kidney Dis Transpl. 2017;4:830-5.

10. Nur S, Albar H, Daud D. Prognostic factor for mortality in pediatric acute post streptococcal glomerulonephritis. Paediatr Indones. 2016;3:167.

11. Shah G. Post infective glomerulonephritis in children a hospital based study. Journal of Patan Academy of Health Science.
2017;4:26-31.

12. Blum HL. Expanding Health Horizons: From a General Systems Concept of Health to a National Health Policy. Oakland, California; Third Party Publishing Company, 1983.

13. Kliegmen RM. Acute poststreptococcal glomerulonephritis. In: Pan CG, Avner ED, editors. Nelson Text Book Pediatrics (12th ed). Canada: Elsevier, 2016; p. 2500-1, 1487-8.

14. Fadholi A. BMKG. Hujan dan kemarau menurut Badan Meteorologi Klimatologi dan Geofisika. 11 Nov 2012 [cited 2017 Nov 23]. AVAilable from: http://www.ift.or.id/2012/11/ hujan-dan-kemarau-menurutbadan.html

15. Nur S, Albar H, Daud D. Prognostic factor for mortality in pediatric acute post streptococcal glomerulonephritis. Paediatr Indones. 2016;3:167.

16. Badan Penelitian dan Pengembangan Kesehatan. RISKESDAS dalam angka. 13 Mei 2015 [cited 2017 Dec 12]. Available from: terbitan.litbang.depkes. go.id/penerbitan/index.php/lpb/catalog/ book/158. 